This is an Accepted Manuscript of an article published by SAGE in Environment and Planning B: Urban Analytics and City Science: https://journals.sagepub.com/doi/full/10.1177/2399808319869341

Wurm, M., Goebel, J., Wagner, G. G., Weigand, M., Dech, S., \& Taubenböck, H. (2019). Inferring floor area ratio thresholds for the delineation of city centers based on cognitive perception. Environment and Planning B: Urban Analytics and City Science. https://doi.org/10.1177/2399808319869341

\title{
Inferring floor area ratio thresholds for the delineation of city centers based on cognitive perception
}

\author{
Michael Wurm ${ }^{1}$, Jan Goebel ${ }^{2}$, Gert G. Wagner ${ }^{2,3}$, Matthias Weigand ${ }^{1}$, Stefan Dech ${ }^{1,4}$, \\ Hannes Taubenböck ${ }^{1}$ \\ ${ }^{1}$ German Aerospace Center (DLR), German Remote Sensing Data Center (DFD), 82234 Oberpfaffenhofen, Germany. \\ ${ }^{2}$ German Socio-Economic Panel Study (SOEP), German Institute of Economic Research (DIW Berlin), 10117 Berlin, \\ Germany. \\ ${ }^{3}$ Max Planck Institute for Human Development, 14191 Berlin, Germany. \\ ${ }^{4}$ University of Würzburg, Department of Remote Sensing, Institute of Geography and Geology. 97074 Würzburg, \\ Germany.
}

\begin{abstract}
The morphology of today's cities is the result of historic urban developments and ongoing urban transformation resulting in complex urban spatial structures. While functionally as well as spatially, cities are structured into sub-units such as the city center, business districts, residential areas or industrial and commercial zones, their precise localization in the geographic space is sometimes difficult. City centers in particular are difficult to grasp because they stand for many different urban functions. Generally, they are characterized as areas of high densities, such as employment, population or commerce, but also as areas of high structural densities. In past studies, various approaches, data and cut-off values have been presented to separate city centers from the surrounding transition zones in geographical information systems based on density values. To overcome the difficulty in defining the right density threshold, the current study presents an approach which integrates the subjective perception of citizens on the urban spatial structure and relate it to the floor area ratio to delineate city centers to infer a characteristic density threshold. In a large empirical study for 67 monocentric cities in Germany we observe a decreasing floor area ratio gradient towards the urban fringes. The result of the study reveals a relative threshold for city centers at around $30 \%$ of the density of the 'central place'.
\end{abstract}

\section{Keywords}

city center; cognitive perception; urban spatial structure; density; floor area ratio. 


\section{Introduction}

The spatial structure of cities has undergone fundamental transformations over the past centuries. Today's cities appear often as decentralized, polycentric (Garreau 1991) urban structures; they are sometimes even seen as an intermediate step to a dispersed urban world (Batty et al. 2004). This is mostly a result of planning policies in the $20^{\text {th }}$ century where urban functions have been segregated and decentralized shaping modern cities as complex urban systems connecting urban functions and urban forms throughout spatial and functional networks (Batty 2008). While these described processes are mainly observed in North America and recently in Asia, European cities mostly still resemble what they looked like "in the lifetime of St. Thomas Aquinas [...] built in the $13^{\text {th }}$ century" (Holmes 1992). Medieval European cities were characterized as places with a mix of urban functions (e.g. housing, trade and commerce, consumption, employment) in very close spatial proximities resulting in the majority of jobs being concentrated in central manufacturing areas (Anas, Arnott \& Small 1998). Since city sizes were regulated by walking or horseback riding distances, spatial congruency between these functions could be enabled inside city walls which were constructed in the shortest, thus in a circular shape around a 'central place' which served as nuclei of urban development, e.g. the central market (Schluiter 1899). This has led to the development of monocentric urban spatial structures in European cities which could be preserved until the $19^{\text {th }}$ century when the Industrial Revolution gave way to new usages of urban spaces and processes of deconcentration and suburbanization gained in prevalence (Siedentop 2005). A key prerequisite for the latter was the decreasing importance of spatial proximity as a necessity for economy due to new transport technologies. Thus, the importance of the historical city centers in terms of trade and commerce has eventually declined over time (Besussi and Chin 2003; Thomas \& Bromley 2003; Schiller 2001), but they are still important for the provision of urban functions and soft economies today, favoring high density and mixed locations (Batty et al. 2004).

In fact, high density and high diversity are considered as the most important characteristics when defining city centers. Most commonly, functional characteristics are used to define and delineate city centers, such as high concentrations of commerce, economic activities, employment, high individual and public traffic (including pedestrians) as well as high diversity of activities and touristic attractions, respectively (Sert 1952; Murphy \& Vance 1954; Anas, Arnott \& Small 1998; Thurstain-Goodwin \& Unwin 2000, McMillen 2004). Besides urban functions, also morphological characteristics were used to delineate city centers, mostly in terms of structural density (Murphy \& Vance 1954; Murphy 1972; Taubenböck et al. 2013 \& 2016; Krehl et al. 2016). As a result of this plurality of characteristics for defining city centers, a commonly agreed and consistent definition of city centers has not evolved (Ralphs \& Wyatt 2003), and moreover, no commonly accepted density threshold has been found.

This ambiguity in defining and delineating city centers is addressed in the present paper. We aim at taking up on the fuzziness for delineating city centers by analyzing cognitive perceptions of citizens on city centers and relate it to the floor area ratio (FAR) to empirically infer a density threshold value for separating city centers from the transition zone. In this way, we analyze people's cognitive perceptions to spatially define city centers, since citizens recognize and realize the presence of a city center when they are 
standing in a city center even if they cannot define it. The use of subjective perception to create 'mental maps' has been introduced by Lynch (1960) where he describes the concept of 'legibility', making parts of the city recognizable to its dwellers and thus triggers to spatially organize the city in the sense of mental maps. They are a subjective interpretation of the environment as a function of individual social values and constraints (Rengert \& Pelfrey 1997). This concept is related to the direct perception theory (Gibson 1979) where specific objects are related to specific functions or activities. For example, a park affords relaxing or a street affords walking (Jiang 2012). In this way, a city creates also a mental map for citizens (Haken \& Portugali 2003). Based on these concepts, we search empirically for a characteristic degree of FAR which is commonly accepted by citizens to separate city centers from their surrounding areas. Thus, this paper contributes to research on the delineation of city centers. The work provides new perspectives on delineating city centers following an empirical, quantitative analysis of 67 monocentric major cities in Germany. In an experimental setting, we calculate structural density represented as FAR based on 3D building models and relate it to cognitive perceptions of citizens on the city center. To demonstrate the proof of concept, we divide the statistical population of all cities into 4 groups based on population density since it provides a proxy value for the urban spatial structure. We argue feasibility of this proof of concept if the empirically derived distances are similar among the 4 groups.

The remainder of this article is structured as follows: we begin by reviewing how city centers are defined and localized in previous studies based on functional and morphologic features (Section 2). The following Section 3 describes the used data and the workflow for the calculation of urban morphologic features such as the floor area ratio and the integration of survey data on cognitive perception of city centers. This is followed by a discussion on the proposed analysis in Section 4 and, finally, Section 5 concludes the paper with an outlook.

\section{Delineation of city centers: related work}

To delineate city centers, we need to have an understanding of how and based on which criteria they are separated from their surrounding areas. But these surrounding 'zones of transition', as introduced in the classical models of urban land-use (Park, Burgess \& Ernst 1925), remain also rather fuzzy in definition and shape. They are described as areas with lower densities than the city center, e.g. population density (Borruso \& Porceddu 2009) and also lower land prices as a function of the accessibility to the central business district (CBD) as introduced in the classical, monocentric urban bid rent model by Alonso (1964) and still applied in current studies (D'Acci 2019). From the aspect of historical urban development, the transition zone represents the former suburbs of the historic city, mostly located outside former city fortifications. In some cities, these fortifications could be preserved until today e.g. Neuf-Brisach (France) or Lucca (Italy), and still delimit a sharp border between the city center and its surroundings, mostly visible by significant differences in density (Figure 1-A). In other cases where the city walls have been torn down, we find today other structuring elements in their place such as boulevards e.g. the 'Ringstraße' in Vienna (Austria), the 'boulevard périphérique' in Paris (France) or parks 
e.g. Cologne (Germany) which still keep the separating function of the former city walls alive, mostly still visible by changing morphological densities (Figure 1-B). Another example are cities with no more clearly visible separating element in their today's urban spatial structure between their former city centers and their surroundings since their urban morphology has been transformed more severely over the past centuries (Figure 1-C), e.g. due to large-scale destruction and rebuilding e.g. Rotterdam (The Netherlands). In these cases, the physical circumscription of the city center cannot be easily identified since the transition zone is an area of flux which is characterized by a continuous change in urban function or land-use as well as a decrease in density without any obvious threshold.
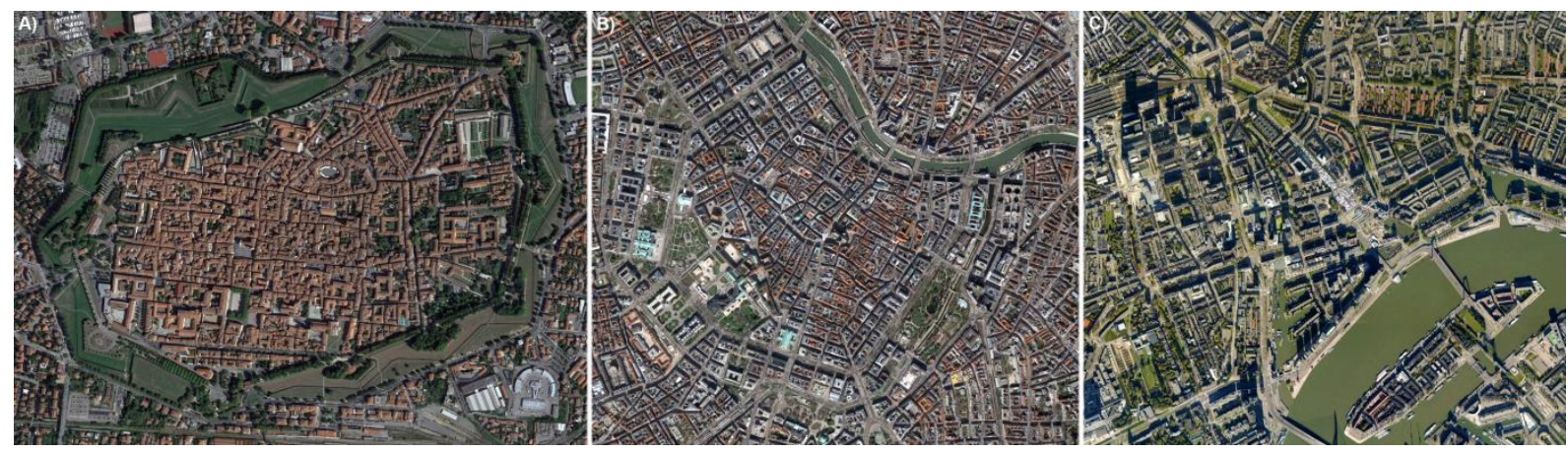

Figure 1: Examples for city centers: A) preserved city walls: Lucca (Italy). B) former walls replaced by structuring elements such as boulevards: Vienna (Austria). C) entirely transformed: Rotterdam (The Netherlands). () Google Earth.

From a scientific point there exists neither a single, commonly agreed feature nor cut-off value to delineate the city center from its surroundings. Due to the fuzziness of city centers, the use of geographical information systems for their delineation has been criticized for a long time (Taylor 1995), although more recent approaches have successfully addressed this issue (Batty et al. 2004). In related work, city center detection was performed based on a large spectrum of features, such as functional characteristics (Thurstain-Goodwin \& Unwin 2000; Lloyd 2009; Borruso \& Porceddu 2009), travel flows (Ratti et al. 2006; Roth et al. 2011), location-based social networking (Sun et al. 2015), social media data (Hollenstein and Purves 2010; Chen et al. 2017), urban land use data (Zhu \& Sun 2017), points of interest and road network data (Lei et al. 2015; Yu et al. 2015). Besides functional characteristics, also morphological features such as the density were used to delineate CBDs (Murphy \& Vance 1954; Taubenböck et al. 2013; Krehl et al. 2016). These related works approach city center delineation either in terms of a clearcut spatial delineation based on a broad set of different kinds of data or approach the fuzziness of city centers understanding it as higher order geographical phenomenon. In this way, Burrough \& Frank (1996) find city centers based on the cognitive perception of citizens such as mental maps, as introduced by Lynch (1960). The approach of using social studies' participants' individual perception for spatially structuring urban areas by the features location, density and function was successfully adapted by HoffmeyerZlotnik (2000). Further studies related citizens' perceptions to the appearance of specific urban functions of city centers (Le et al. 2005; Lüscher and Weibel 2012; Alarasi, Martinez \& Amer 2015), assessed the quality of a center (Rengert \& Pelfrey 1997) or 
delineated the area of city centers for a small number of cities (Montello et al. 2003; Lüscher and Weibel 2012; Le et al. 2005). Despite the related work in this context, one remaining drawback is that the individual choice of criteria for describing a city center remains very subjective for each individual. Thus, it is very unlikely that two citizens agree on a similar set of criteria (Thurstain-Goodwin \& Unwin 2000) making the search for an optimal feature set a very difficult task. Therefore, instead of searching for a commonly accepted set of functional criteria to delineate city centers for all cities under investigation, we base our approach to citizens' perceptions on their household locations to delineate city centers and relate it to the FAR as a very visible and objective criterion. Moreover, we aim at finding a generalizable, characteristic FAR-threshold for separating city centers from their surroundings.

\section{Data and methods for delineating city centers}

The proposed workflow for empirically inferring a characteristic FAR threshold to delineate city centers is based on citizens' perceptions and decreasing FAR gradients in monocentric cities (Barr and Cohen 2014). To evaluate the proposed proof of concept, we base our study on a large sample of major cities in Germany. Selection of sample cities was based on several criteria: (1) a minimum population size of 100,000 inhabitants to ensure a significant size of the city center and the transition zone, (2) a monocentric urban structure following a radial FAR gradient, (3) a historic city center to avoid recently planned city foundations and (4) their spatial development has not been too impaired by natural barriers such as mountains or water surfaces. All German major cities have been individually evaluated with regards to their historic development and their urban spatial structure based on (historic) maps and satellite images. Cities which have undergone significant territorial reforms (e.g. Berlin, Wuppertal, Remscheid), with decreasing population sizes (e.g. Zwickau, Wilhelmshaven), with a spatial development which is affected by natural barriers such as the sea (e.g. Bremerhaven, Kiel, Flensburg) or cities without a historical city center (e.g. Wolfsburg, Karlsruhe, Leverkusen, Ludwigshafen) have been removed resulting in a total of 67 major cities in for the current study. For the selected cities, 3D building models are used to calculate the FAR on the spatial level of city blocks. Further, citizens' perceptions from a socio-economic survey are used to spatially delineate the extent of city centers. In a consecutive step, the spatial extents of the perceived areas of city centers are spatially superimposed with the values to infer a characteristic FAR-threshold value at the edge between the city centers and the transition zone. In the absence of objective validation data for the size of city centers, we test the proof of concept with the help of creating 4 groups from the 67 cities based on the following assumption: if the inferred FAR-threshold values are similar among these groups, an interrelation between FAR and cognitive perception on city centers can be argued. The 4 groups are based on the population density of the 67 cities since the population density integrates both, population size and area of a city. Using Jenks' natural breaks classification algorithm (Jenks and Caspall 1971), the following 4 groups are created: 1) $\leq 850 \mathrm{inh} . / \mathrm{km}^{2}$, 2) $850-1600 \mathrm{inh} . / \mathrm{km}^{2}$, 3) $1600-2500 \mathrm{inh} . / \mathrm{km}^{2}$ and 4) $>2500$ inh. $/ \mathrm{km}^{2}$. The proposed workflow is presented in detail below and an overview of the required steps is depicted in Figure 2. 


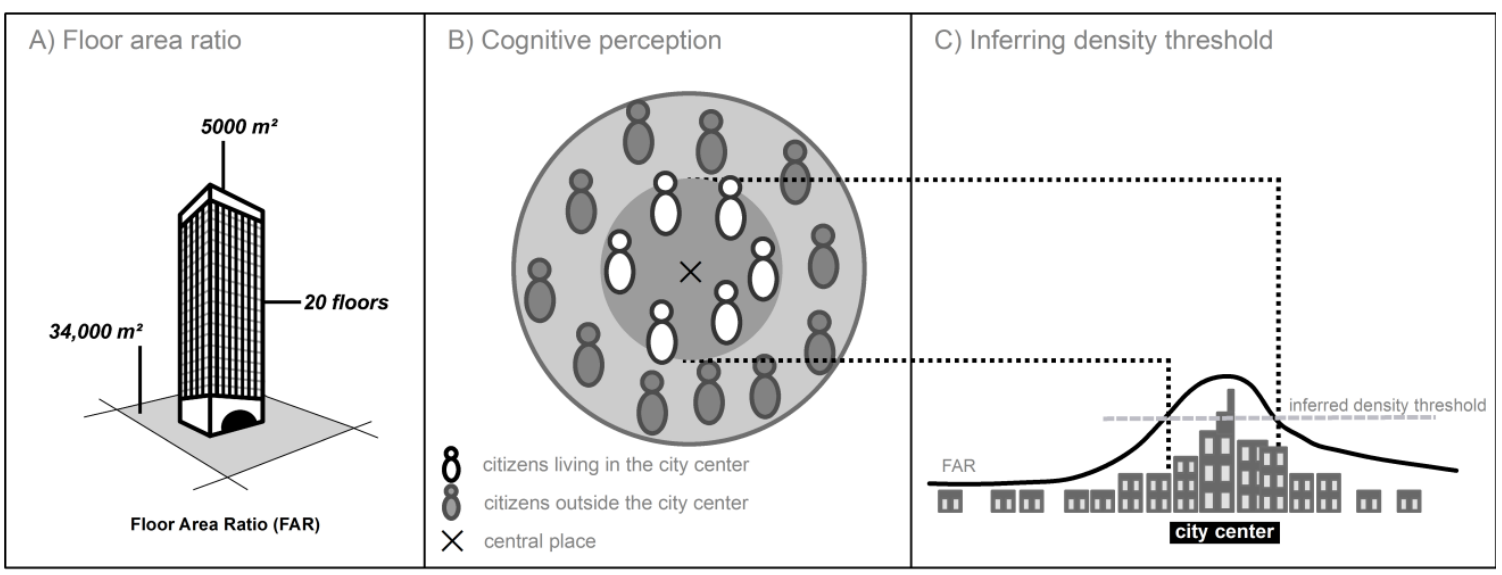

Figure 2: Workflow for delineating city centers based on FAR and cognitive perception: A) Calculation of FAR (Section 3.1); B) Using citizens' perceptions to delineate city centers (Section 3.2); C) Inferring the FAR-threshold (Section 3.3).

\section{1 - Calculation of FAR}

Structural density represents a key feature for the characterization of urban morphology and is crucial for describing urban activities (e.g. Acioly \& Davidson 1996). It stands for proximity because with rising density of a city, distances are decreasing and citizens cover more distances walking in the city, by bike or public transport. Density serves as a trigger for synergies and concurrences, thus having a positive impact on prosperity and innovation. Despite its wide application in urban studies and planning, structural density still represents a fuzzy concept (e.g. Krehl et al. 2016; Taubenböck et al. 2016). For its calculation, usually building footprint areas or volumes are related to the area of the land lot or the city block. An objective and comparable measure of structural density for analyzing the urban spatial structure represents the floor area ratio (FAR) (Barr \& Cohen 2014; Wurm et al. 2014). It is defined as the ratio of total usable floor space to the size of the plot, e.g. the FAR of a plot with a 5-story building constructed over the entire plot would equal to 5, while a 10-story building over half the plot size would also equal to 5 (Barr \& Cohen 2014). For the current study, FAR is calculated based on ministerial 3D building models at the Level-of-Detail-1 (LoD-1) and data on city block geometries. LoD-1 building models represent the shape of buildings as block model incorporating building footprint geometries (e.g. area) and a metric building height value, however these data usually do not incorporate the number of floors. Thus, these data represent a simple 3D representation of buildings. For detailed information on the related LoD-1 building model, we refer to the official product catalogue for federal agencies on the website of the data provider ${ }^{1}$. Since for calculation of FAR, the buildings' areas and the number of floors are required, we infer the number of floors based on empirically established linear regression models with a sample of 600,000 buildings including data

1

http://www.geodatenzentrum.de/geodaten/gdz rahmen.gdz div?gdz spr=eng\&gdz akt zeile=2\&gdz an z zeile $=0 \& g d z$ user id=0 (LoD-1 description can be found on page 25, documentation in German). 
on metric height and number of floors. The approach for inferring floor numbers based on LoD-1 building models is related to Wurm et al. (2011) and Krehl et al. (2016) and we refer to these studies for a detailed description of the workflow. The model is validated in a two-fold cross validation procedure, yielding an adjusted $R^{2}$ of 0.746 . After application of the model to all 9.5 million individual buildings, FAR is calculated for all 417,000 city blocks in all 67 cities (Figure 3). Since the range of FAR values varies significantly among the cities, we use the normalized FAR for better comparability. Normalized FAR $\left(F A R_{N}\right)$ values are calculated in relation to the FAR around the 'central places', where usually the highest densities are found in monocentric cites. Thus, $F A R_{N}$ is set to 1.0 for all cities at the 'central place' and all other density values for the same city are related to this density. As a result, decreasing $F A R_{N}$ gradients between the city center and the periphery are observed. The gradients vary also significantly between cities of varying sizes, e.g. in cities with higher population densities, higher FAR values are observed.

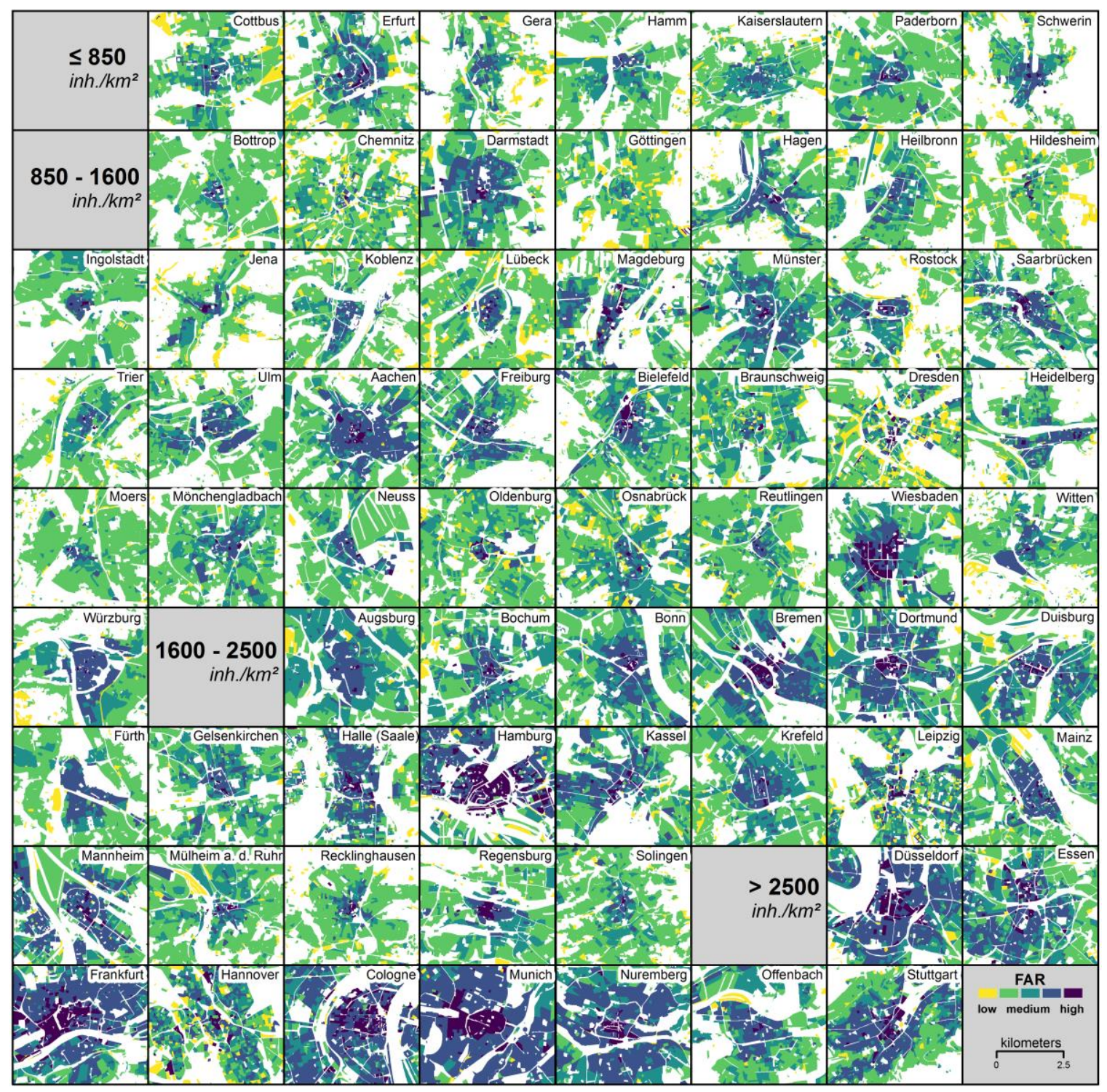

Figure 3: Floor Area Ratio (FAR) for all 67 cities of the study, presented in 4 groups of population density. 


\section{2 - Cognitive perception of citizens}

For all 67 cities in this study, we use cognitive perception of citizens to create a common understanding of the size of the city centers. These 'mental maps' are based on national household survey data from the Socio-Economic Panel Study (SOEP) on more than 23,000 individuals in about 11,000 households in Germany (Goebel et al. 2018). In SOEP, detailed socio-economic data about objective and subjective life conditions are surveyed on a yearly basis. One question asks participants to locate their house in the city as being located either 'in the city center' or 'outside the city center'. In total, 2865 households, claim to live in a city center. For each citizen's house located in the city center, the distance between the geographic location of the house and the 'central place ${ }^{2}$, is calculated using anonymized geographically referenced household data ${ }^{3}$ (Goebel \& Pauer 2014). In a last step, the mean distance value for all households is calculated. This distance value stands for the commonly perceived size of the spatial extent of the city center by the citizens. In the following analysis step in Section 3.3, this distance value is used to infer the FAR-threshold. Figure 4 displays the households' distances to the 'central places' for each population density group: with rising population density, also the distances to the central place rise for the households claiming to live in the city center. For inferring the FAR-density threshold (Section 3.3), the mean distance values are used for the 4 groups: 1) $1.40 \mathrm{~km}, 2) 1.94 \mathrm{~km}, 3) 2.55 \mathrm{~km}$ and 5) $2.85 \mathrm{~km}$.

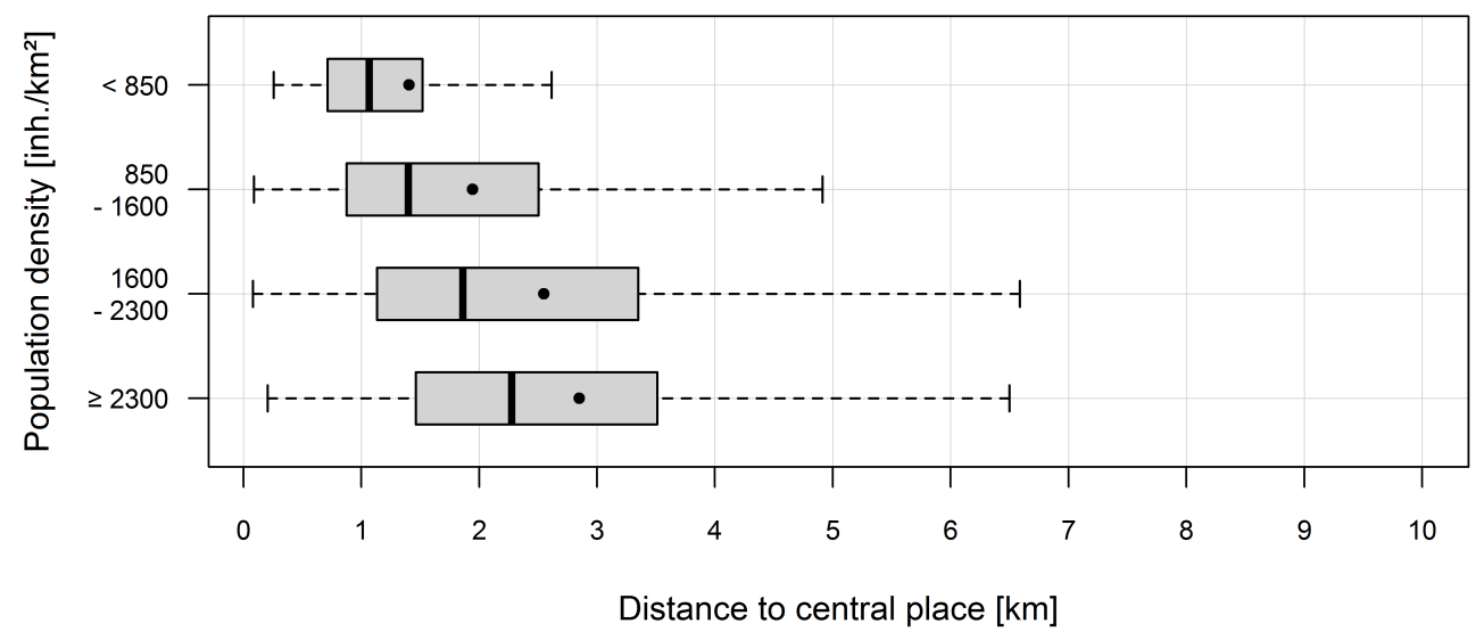

Figure 4: Boxplots of distances between geographic locations of households and the 'central place' grouped by the population density. The mean distance values are depicted as black dots inside the boxes.

\footnotetext{
${ }^{2}$ While city centers usually represent areas, e.g. the medieval city, 'central places' are e.g. a central market around which the urban development took place.

${ }^{3}$ SOEP data is strongly protected by personal security terms. No information of geographic position of interviewees is accessible to the data analyst.
} 


\section{3 - Inferring the FAR-threshold}

In this step, derived distances based on citizens' perceptions and normalized FAR-density $F A R_{N}$ are mutually analyzed for inferring the threshold to delineate city centers from the surrounding transition zone. The threshold is inferred at the intersection of the distance value with the $F A R_{N}$ modeled gradients for each of the 4 city groups. The modelled functions are characterized by a smoothing effect which can suppress local changes of the density measure, e.g. one tall building in the transition zone. Best fitting functions were sought as exponential functions. The $F A R_{N}$ gradients are modeled for each of the 4 groups separately (Figure 5). Goodness of fit for the modeled functions is measured as $R^{2}:$ 1) $\left.\left.0.985,2\right) 0.992,3\right) 0.985$ and 4) 0.985 .

The shape of the modeled functions varies between the 4 groups, e.g. $F A R_{N}$ decreases at shorter distance from the 'central place' towards the periphery for smaller cities than for larger cities (Figure 5): e.g. FAR at a distance of $1.5 \mathrm{~km}$ varies between 0.35 and 1.0 for city group 1 and group 4, respectively. Consequently, similar FAR values can be found at varying distances between the groups. We make use of this observation in our proof of concept in the following way: if the inferred FAR values are similar among the 4 city groups, we argue that structural density influences citizens' cognitive perception on city centers to a certain degree.

Inferred FAR-values for the 4 groups are depicted in Figure 5. The derived subjective distances to the central place vary between $1.4 \mathrm{~km}$ (for the lowest population densities in the first group) and $2.85 \mathrm{~km}$ (for the highest population densities in the last group). This accounts for an almost $250 \%$ difference in distance from the 'central place' across the 67 sample cities. Regarding the inferred $F A R_{N}$ values at the intersections, however, very similar values can be observed despite the large difference in distances: 1$)<0.33,2$ ) $0.28,3) 0.26$ and 4) 0.30 . Over all 4 groups, only very small differences in the $F A R_{N}$ values are observed. Based on these inferred density values for the 4 groups, we observe $F A R_{N}$ thresholds of approximately 0.3 for delineating city centers from the transition zone. As this threshold is tested for a large sample of 67 cities, it appears to be independent from varying city sizes or their spatial extent, respectively. 


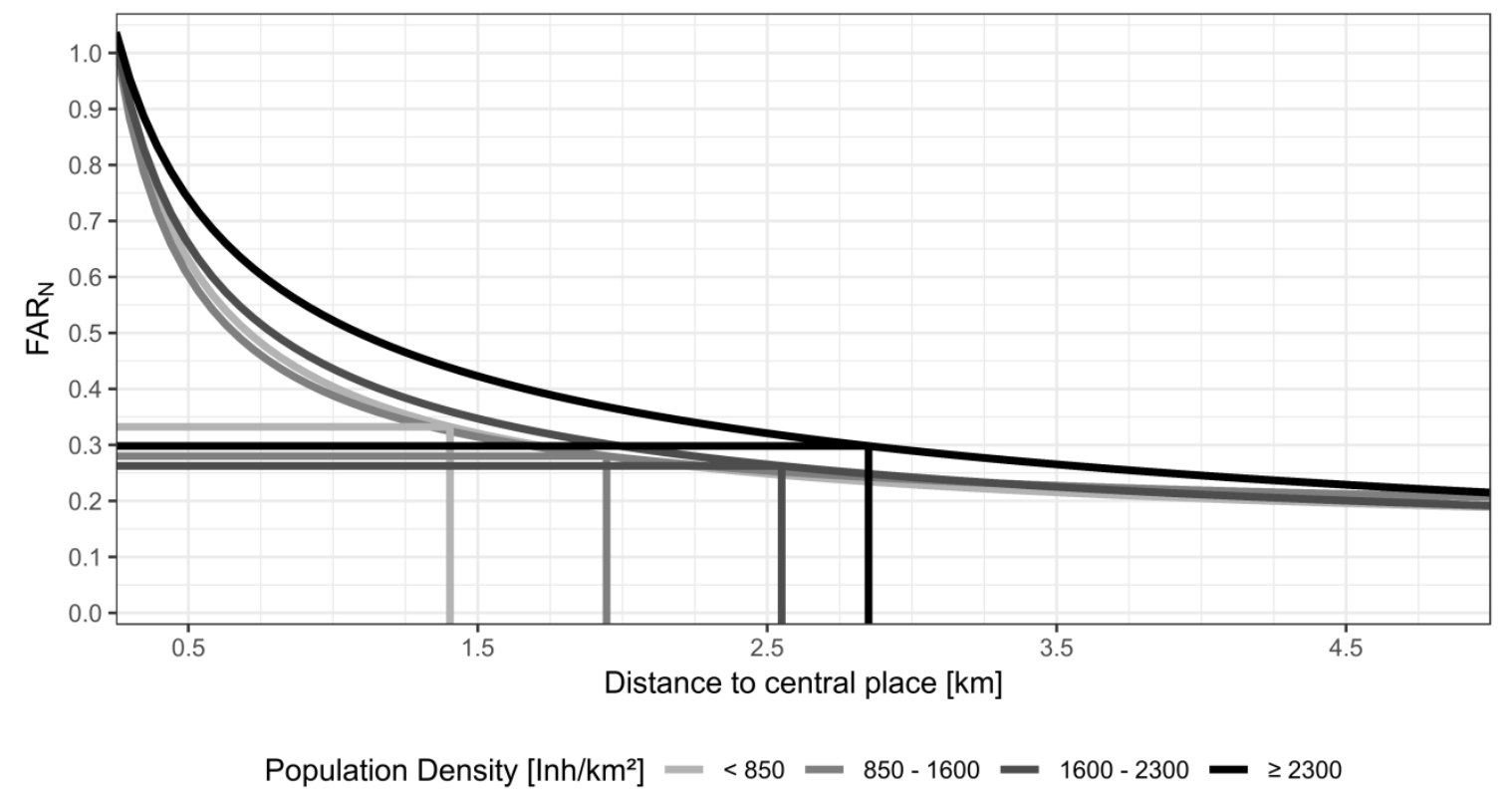

Figure 5: Inferred FAR-thresholds for the 4 population density classes: gradients represent an exponential function of the decreasing $F A R_{N}$ densities and the vertical bars represent the derived subjective distances as presented in Figure 4. The horizontal bars indicate the inferred FAR-value at the intersection point between the subjective distance and the FAR gradient. The difference in distance (x-axis) varies to a much larger degree than the difference in inferred FAR (y-axis).

\section{Discussion of empirical findings}

\subsection{General remarks on the approach}

What from an initial perspective seems to be a very trivial issue - pointing a city center on a map - becomes easily very complex when generalized descriptions and spatial circumscriptions of city centers are sought. While historical walled cities made a precise spatial demarcation of the city a feasible task, morphological transformations of the urban spatial structure and observed deconcentration processes of urban functions towards polycentric urban structures in European cities complicate this task to a high degree. The debate on defining and spatially delineating city centers takes up on the debate on the fuzziness of geographical places in urban areas which are more or less only qualitatively defined or are merely just spatial concepts at higher level. The underlying challenge of this ambiguity in definitions comes to light especially when entirely different aspects of these geographical places are addressed, such as functional and morphological characteristics. While their precise definition and thus also their spatial delineation is subject to such a broad heterogeneity among scholars, their presence in urban areas cannot be neglected. For most of those geographical concepts it holds true that they are "hard to define, but you know it when you see it" (Cervero 2000). This perspective on the issue follows the empirical research on central places, which aims at exploring the 
organization of urban systems in an analytical way without the restrictions of formal theory (Burger \& Meijers 2012).

In the direction of these related studies, we also embed the presented study on cognitive perception and the urban spatial structure. This study presents an empirical approach to link cognitive perceptions of citizens and the structural density of cities. In this way, the concept of mental maps is integrated into the study design. Mental maps are very relevant because every citizen has his/her own individual perspective of the urban spatial structure and the location as well as the spatial circumscription of the city center. The individual perception of the location and extension of the city center is influenced by each citizen's unique subjective, personal history and understanding of the urban spatial structure (Rengert \& Pelfrey 1997). From the vast amount of morphological or functional attributes which characterize city centers, each citizen structures the city wittingly or unwittingly in his/her mind.

The presented approach allows for integrating a larger quantity of samples and cities than approaches using in-depth interviews. The latter mostly aim at precise spatial circumscriptions of city centers drawn by participants on a map, mostly as a case-study for just one or a few cities (e.g. Lüscher and Weibel 2012). These approaches may eventually lead to higher spatial precision and they can be analyzed in geographical information systems, but results are mostly restricted to a handful of case studies. Contrarily, our approach cannot predict a precise delineation for individual cities, but aims at associating urban structure and density on a more generalizable level. Therefore, it must be underlined that the inferred distances from cognitive perceptions cannot be transferred back to single cities for comparison with the actual situation since there is only one value for all cities from the same group of population density.

For a meaningful interpretation of this empirical study, general preconditions must be considered and therefore we highlight the following points:

- the approach derives a Euclidian distance for finding the extent of city centers. Since only one distance is used, a radial extension of the city center around the most 'central place' is assumed together with a circular circumscription of the transition zone around it. Hence, the approach requires the assumption of a monocentric city model which can be more or less accepted for most German cities with similar historic city development (Schluiter 1899). A linear transfer of the approach to cities with a completely different urban spatial structure, e.g. to polycentric urban structures appears at this point under consideration of the used data not feasible.

- for all cities where a discrete delineation of the city center is not possible, a precise association of the respective functional and morphological urban areas into city center and transition zone is beyond feasibility since these measures do not follow a strict concept. Moreover, in today's cities the transition between the city center and the transition zone is mostly continuous. Therefore, approaches for finding city centers use selected physical and/or functional, quantifiable characteristics of city centers. The perception of citizens integrates all objective and subjective characteristics of each individual's surroundings. Thus, the vast number of attributes influencing people's perception is difficult to fit into a model. To account for all these features, the current study relates to citizens' cognitive perceptions of the city center by the location of their houses. 


\subsection{Findings}

In due consideration of the above mentioned aspects, the presented empirical study aims at relating the urban spatial structure to the cognitive perception of citizens. Cognitive perceptions of 2865 households living in a city center are analyzed with regard to their distances to the most 'central place' of each city. Subsequently, the derived distance is used to delineate the city centers and intersected with the FAR gradient to infer a FARthreshold for separating city centers from the transition zone. For comparability between cities, we use the normalized floor area ratio $F A R_{N}$ which is represented as a decreasing density gradient from the most 'central place' towards the periphery. The inferred FARthreshold values are very similar for all cities among the 4 groups of city sizes: they range between $67-74 \%$ of the density of the most 'central place' for all cities. In other words: we argue that structural density might play a role in the cognitive perception of citizens for separating city centers from the transition zone.

\section{Conclusion and outlook}

The empirical experiments in this study indicate a relation between structural density and cognitive perception of city centers. The study brings data of great heterogeneity together for seeking new insights on the complex urban spatial structure. In detail, the interdisciplinary analysis of spatial and non-spatial data in form of geographical information system data and socioeconomic surveys are combined. With respect to the data, we performed the analysis for 67 cities with 9.5 million individual buildings to calculate the floor area ratio. Furthermore, individual responds from 11,000 households participating in the SOEP were used to analyze the city centers providing a very large data base for the experimental setup of study.

For related studies in the future, to gain even more reliable and transferable results, we propose the use of a higher spatial density of household observations. Furthermore, with respect to future works, while this approach was empirically set-up and tested for German cities with similar historic developments, a comparison to cities with different historic development would be of great interest, e.g. to North-American cities featuring CBDs or polycentric urban structures; however, the generation of a representative amount of households data on the individual perception might be the limiting factor. Further, since the current study focuses solely on the morphologic aspects of the urban spatial structure, we propose to extend the study by the integration of additional, functional characteristics, e.g. employment density or commerce.

\section{Funding}

The authors received no financial support for the research, authorship, and/or publication of this article. 


\section{References}

Acioly C and Davidson F (1996) Density in urban development. Building Issues 8:3-25.

Alarasi H, Martinez J and Amer S (2016) Children's perception of their city centre: a qualitative GIS methodological investigation in a Dutch city. Children's Geographies 14 (4): 437-452.

Alonso W (1964) Location and Land Use, Cambridge: Harvard University Press, https://dx.doi.org/10.4159/harvard.9780674730854

Anas A, Arnott R and Small KE (1998) Urban spatial structure. Journal of Economic Literature, American Housing Association. 36(3): 1426-1464.

Barr J and Cohen JP (2014) The floor area ratio gradient: New York City, 1890-2009. Regional Science and Urban Economics 48: 110-119.

Batty M (2008) The size, scale, and shape of cities. Science 319: 769-771

Batty M, Besussi E, Maat K and Harts JJ (2004) Representing multifunctional cities: Density and Diversity in Space and Time. Built Environment 30(4): 324-337.

Besussi, E and Chin, N (2003). Identifying and measuring urban sprawl. In: Longley, PA and Batty, M (eds): Advanced Spatial Analysis: The CASA Book of GIS, pp. 109-128.

Borruso G and Porceddu A (2009). A Tale of Two Cities: Density Analysis of CBD on Two Midsize Urban Areas in Northeastern Italy. In: Murgante B, Borruso G, Lapucci A (eds) Geocomputation and Urban Planning. Studies in Computational Intelligence 176. Springer, Berlin, Heidelberg

Burrough PA and Frank AU (1996) Geographic objects with indeterminate boundaries. London, Taylor \& Francis

Burger M and Meijers E (2012) Form Follows Function? Linking Morphological and Functional Polycentricity. Urban studies 49 (5): 1127-1149.

Cervero R (2000) Shapeless, Spread Out, Skipped Over and Scattershot - Sprawl Sweeps the Globe. In: The World Paper, pp. 5-6.

Chen Y, Liu X, Li X, Liu X, Yao Y, Hu G, Xu X and Pei F (2017) Delineating urban functional areas with building-level social media data: A dynamic time warping (DTW) distance based k-medoids method. Landscape and Urban Planning 160: 48-60

D’Acci (2019) Quality of urban area, distance from city centre, and housing value. Case study on real estate values in Turin. Cities: in press.

Garreau J (1991) Edge City: life on the new frontier. New York City: Doubleday.

Gibson JJ (1979) The Ecological Approach to Visual Perception, Houghton-Mifflin: Boston, MA.

Goebel J and Pauer B (2014) Datenschutzkonzept zur Nutzung von SOEPgeo im Forschungsdatenzentrum SOEP am DIW Berlin. Zeitschrift für amtliche Statistik Berlin Brandenburg 3: 42-47. 
Goebel J, Grabka MM, Liebig S, Kroh M, Richter D, Schröder C and Schupp J (2018) The German Socio-Economic Panel Study (SOEP). Jahrbücher für Nationalökonomie und Statistik / Journal of Economics and Statistics (online first), doi: 10.1515/jbnst-20180022

Haken H and Portugali J (2003) The face of the city is its information, Journal of Environmental Psychology 23(4): 385-408.

Hollenstein L and Purves RS (2010) Exploring place through user - generated content: Using Flickr to describe city cores. Journal of Spatial Information Science 1(1): 21-48

Holmes G (2001) The Oxford illustrated history of Medieval Europe, Oxford: Oxford University Press.

Hoffmeyer-Zlotnik JHP (2000) Regionalisierung sozialwissenschaftlicher Umfragedaten, Wiesbaden: Westdeutscher Verlag.

Jiang B (2012) Computing the image of the city. In: Campagna M, De Montis A, Isola F, Lai S, Pira C and Zoppi C (eds) Planning Support Tools: Policy analysis, implementation and evaluation, Proceedings of the 7th Int. conf. on Informatics and Urban and Regional Planning INPUT 2012, 111-121.

Jenks G F, Caspall F C (1971) Error on Choroplethic Maps. Defnition, Measurement, Reduction. Annals of the Association of American Geographers 61: 217-244.

Krehl A, Siedentop S, Taubenböck H and Wurm M (2016) A Comprehensive View on Urban Spatial Structure: Urban Density Patterns of German City Regions. ISPRS International Journal of Geo-Information 5(76), https://dx.doi.org/10.3390/ijgi5060076

Le T, Abrahart R, Aplin R and Priestnall G (2005). Town centre modelling based on public participation, In: CUPUM 05, Computers in Urban Planning and Urban Management - 9th international Conference, London.

Lei Y, Tian J, Lin L and Ren C (2015) A method for automatic delineation of city centers using POI and road networks. Cehui Xuebao/Acta Geodaetica et Cartographica Sinica 44: $42-48$

Lloyd DA (2009) GIS-based applications and the English Planning system: modeling town centers and housing potential, In: Steinebach G, Guhathakurta S, Hagen H (eds): Visualizing Spatial Planning, Springer.

Lüscher P and Weibel R (2012) Exploiting empirical knowledge for automatic delineation of city centers from large-scale topographic databases. Computers, Environment and Urban Systems 37: 18-34.

McMillen DP (2004) Employment densities, spatial autocorrelation \& subcenters in large metropolitan areas. Journal of Regional Science 44: 225-243.

Montello DR, Goodchild MF, Gottsegen J and Fohl, P (2003) Where's Downtown?: Behavioral Methods for Determining Referents of Vague Spatial Queries. Spatial Cognition \& Computation: An Interdisciplinary Journal 3(2-3): 185-204

Murphy RE and Vance LE (1954) Delimiting the CBD. Economic Geography 30: 189-22 
Park RE, Burgess EW (1925) The Growth of the City: An Introduction to a Research Project. The City. University of Chicago Press.

Ralphs MP, Wyatt P (2003) GIS in Land and Property Management. Taylor \& Francis

Ratti C, Pulselli RM, Williams S and Frenchman D (2006) Mobile landscapes: Using location data from cell phones for urban analysis. Environment and Planning B: Planning and Design 33(5): $727-748$.

Rengert GF and Pelfrey WV (1997) Cognitive mapping of the city center: comparative perceptions of dangerous places. In: Weisburd D, McEwen T (eds): Crime mapping and Crime Prevention.

Roth C, Kang SM, Batty M and Barthélemy M (2011) Structure of Urban Movements: Polycentric Activity and Entangled Hierarchical Flows. PLoS ONE 6(1): e15923.

Schiller R (2001) The dynamics of property location. Spon Press London: Routledge Chapman \& Hall.

Schlüter O (1899) Über den Grundriß der Städte. Zeitschrift der Gesellschaft für Erdkunde zu Berlin 34(6): 446-461.

Sert JL (1952) The heart of the city. In: Tyrwhitt J and Sert JL (eds): The heart of the city. London, Lund Humphries, pp. 3-16.

Sun Y, Fan H and Zipf A (2015) Identifying the city center using human travel flows generated from location-based social networking data. Environment and Planning B: Planning and Design 43(3): 480-498.

Taubenböck H, Klotz M, Wurm M, Schmieder J, Wagner B, Wooster M, Esch T and Dech S (2013) Delineation of Central Business Districts in mega city regions using remotely sensed data. Remote Sensing of Environment 136: 386-401.

Taubenböck H, Standfuß I, Klotz M and Wurm M (2016) The Physical Density of the City-Deconstruction of the Delusive Density Measure with Evidence from Two European Megacities. ISPRS Int. J. Geo-Inf. 5(11): 206.

Taylor PJ (1995) Geographic information systems and geography. In: Pickles, J. (ed): Ground truth the social implications of geographic information systems, pp. 51-67.

Thurstain-Goodwin M and Unwin M (2000) Defining and Delineating the Central Areas of Towns for statistical Monitoring using continuous surface representations.

Transactions in GIS 4(4): 305-317.

Thomas CJ and Bromley RDF (2003) Retail revitalization and small town centres: the contribution of shopping linkages, Applied Geography 23(1): 47-71.

Wurm M, d'Angelo P, Reinartz P and Taubenböck H (2014) Investigating the applicability of Cartosat-1 DEMs and topographic maps to localize large-area urban mass concentrations. IEEE Journal of Selected Topics in Applied Earth Observation and Remote Sensing 7(10): 4138-4152.

Wurm M, Taubenböck H, Schardt M, Esch T and Dech S (2011) Object-based information fusion using multisensor earth observation data over urban areas. International Journal of Image and Data Fusion 2(2): 121-147. 
Yu W, Ai T, Shao S (2015) The analysis and delimitation of Central Business District using network kernel density estimation. Journal of Transport Geography 45: 32-47.

Zhu J and Sun Y (2017) Building an Urban Spatial Structure from Urban Land Use Data: An Example Using Automated Recognition of the City Centre. ISPRS International Journal of Geo-Information 6(4): 122. 